\title{
Photoperiodic regulation of seasonal testicular regression in the wild European rabbit (Oryctolagus cuniculus)
}

\author{
I. L. Boyd \\ Institute of Terrestrial Ecology, Monks Wood Experimental Station, Abbots Ripton, Huntingdon, \\ Cambs PE17 2LS, U.K.
}

\begin{abstract}
Summary. Adult male wild rabbits were exposed to artificial daylengths of $8 \mathrm{~L}: 16 \mathrm{D}$, 13L:11D or 20L:4D after being taken from the wild during September, when testicular size was minimal. In all groups the testes grew and those in $20 \mathrm{~L}: 4 \mathrm{D}$ grew more quickly than did those in $8 \mathrm{~L}: 16 \mathrm{D}$ or $13 \mathrm{~L}: 11 \mathrm{D}$. Rabbits kept in the 3 daylength treatments for the whole study maintained enlarged testes after the initial growth phase. The testes of rabbits transferred to $13 \mathrm{~L}: 11 \mathrm{D}$ after 8 weeks in 20L:4D did not regress. A similar transfer after 16 weeks in 20L:4D resulted in testicular regression $(P<0.01)$ followed by moult, and then testicular regrowth 9 weeks after the change of daylength. No regression occurred at this time in the control group kept in 20L:4D throughout the study. Plasma FSH concentration increased at the beginning of the study and was elevated during the initial period of testicular growth. Values then declined after the asymptote of testicular weight was reached. Plasma testosterone and LH concentrations did not change significantly throughout the study. The results showed that reproductive regression in wild rabbits can be induced by a reduction in the daylength, but that the potency of this reduction is dependent upon previous experience of daylength.
\end{abstract}

\section{Introduction}

The breeding season in wild European rabbits (Oryctolagus cuniculus) is influenced by the annual cycle of daylength (Boyd, 1985). Like some rodents (Reiter, 1972; Zucker, Johnston \& Frost, 1980; Lynch \& Wichman, 1981), male wild rabbits can, after an appropriate period of exposure to long daylengths, respond to a reduction in daylength by showing a degree of testicular regression and moult followed by a spontaneous testicular regrowth (Boyd, 1985). Under natural conditions, testicular regression occurs during July and August and redevelopment begins between December and March (Andersson, Dahlback \& Meurling, 1979; Henderson, 1979; Davies \& Myhill, 1980; Arthur, 1980; Boyd, 1985). Growth of the testes at the beginning of the breeding season may be equivalent to the spontaneous testicular redevelopment that occurs in rabbits exposed to short days.

Comparisons with other species suggest that a reduction of daylength after stimulation by long daylengths causes male wild rabbits to become refractory to the effect of long daylengths (Hamner, 1968). Exposure to short daylengths then leads to a regained photosensitivity. Short daylengths per se do not normally cause testicular regression because daylengths are still long in July when regression begins. It is not clear why the testes of rabbits should regress after July when, earlier in the year, large testes are maintained in shorter daylengths.

In the Japanese quail, which has a breeding cycle similar to that of wild rabbits when in natural daylengths (Follett \& Maung, 1978; Robinson \& Follett, 1982), the reduction in daylength required to cause photorefractoriness depends upon the previous level of photostimulation (Robinson \& Follett, 1982): the longer the daylength during pretreatment, the greater is the daylength which causes photorefractoriness. Hence, unlike some rodents (Elliott, 1976; Grocock, 1981), rabbits may 
not have a reproductive cycle which is dependent upon the inductive or non-inductive effects of an absolute daylength. Instead, the daylength below which reproductive regression occurs may be determined by the increase in daylength experienced through the spring and early summer.

The aim of this study was to determine whether the previous experience of daylength in male wild rabbits would influence their response to a decline in daylength. This was achieved by pretreating captive wild rabbits with short days followed by different lengths of exposure to long days and, in some cases, a subsequent reduction to an intermediate daylength.

\section{Materials and Methods}

Study animals. Adult male wild rabbits were captured on farmland in Cambridgeshire, U.K., during September 1984. At this time of year male rabbits in the wild have regressed testes but only males with descended testes were used. All 24 rabbits used in this study were kept in natural daylengths until the start of the experiment. Food, which was a standard diet of rabbit pellets, and water were freely available. Rabbits were caged individually in light-proof rooms where daylight was simulated with cold fluorescent strip lamps on the ceiling. Temperature was not closely controlled but varied within the same limits for all rabbits.

Experimental design. The 24 adult male rabbits were pretreated with a photoperiod of $8 \mathrm{~h}$ light:16 h dark ( $8 \mathrm{~L}: 16 \mathrm{D}$; lights on $09: 00 \mathrm{~h}$ ) for 5 weeks from 17 October 1984 . They were then allocated at random to 3 treatment groups. Group 1 (6 rabbits) remained in 8L:16D, Group 2 (6 rabbits) was transferred to 13L:11D (lights on 06:30 h) and Group 3 (12 rabbits) to 20L:4D (lights on 03:00 h. Group 3 was further divided into 3 subgroups each containing 4 rabbits. Group 3a was transferred to $13 \mathrm{~L}: 11 \mathrm{D}$ after 8 weeks in $20 \mathrm{~L}: 4 \mathrm{D}$, Group $3 \mathrm{~b}$ was given the same treatment after 16 weeks in 20L:4D and Group 3c remained in 20L:4D for the duration of the experiment.

Measurements and blood sampling. Measurements of the size of the left testis of all rabbits were obtained at weekly intervals. Testes were manipulated into the scrotum and the total length of the testis, including the head and tail segments of the epididymis, was measured to the nearest $0.1 \mathrm{~mm}$. The maximum testicular width was also measured to the same accuracy and the presence or absence of moult was recorded.

Blood samples were obtained from an ear vein of all rabbits, initially at intervals of 4 weeks and then at intervals of 2 weeks. Each rabbit was given an injection (i.m.) of $0.15 \mathrm{ml}$ Hypnorm, containing fentanyl $(0.20 \mathrm{mg} / \mathrm{ml})$ and fluanisone $(10 \mathrm{mg} / \mathrm{ml})$ (Crown Chemical Company, Lamberhurst, Kent TN3 8DJ, U.K.), 5-10 min before sampling to encourage blood flow to the ears and to induce mild anaesthesia. Blood samples were centrifuged and the plasma stored at $-20^{\circ} \mathrm{C}$.

Testosterone assay. The concentration of testosterone and $5 \alpha$-dihydrotestosterone in the plasma samples was measured by radioimmunoassay. Plasma $(150 \mu \mathrm{l})$ was extracted with $3 \mathrm{ml}$ diethyl ether in a vortex mixer for $15 \mathrm{~min}$ and, after settling, the aqueous phase was frozen. The supernatant was decanted, dried under air and redissolved overnight in $150 \mu$ assay buffer. Labelled testosterone extracted from rabbit plasma gave a mean recovery of $67 \cdot 5 \pm 5 \cdot 3 \%$. Aliquants $(50 \mu 1)$ of extracts were assayed in duplicate with 10 standards ranging from 16 to $0.032 \mathrm{ng} / \mathrm{ml}$. The testosterone antibody cross-reacted with $5 \alpha$-dihydrotestosterone $(100 \%)$ and not to any significant degree with other steroids. Mean assay sensitivity (\% bound with no hormone present $-2 \times$ s.d.) was $0.14 \pm 0.062 \mathrm{ng} / \mathrm{ml}$. The intra- and inter-assay coefficients of variation were 5.5 and $9.0 \%$ respectively. The value of the assay blank (charcoal-stripped rabbit plasma) was less than the sensitivity of the assay.

FSH and LH assays. The concentrations of FSH and LH in samples of rabbit plasma were measured in homologous radioimmunoassays. The unlabelled antigens and antisera were supplied by Dr A. F. Parlow, Harbor-UCLA Medical Center, California 90509, U.S.A. The antigens were 
highly purified rabbit FSH (AFP-538-C) and LH (AFP-7818-C). A modified version of the chloramine-T method (Greenwood, Hunter \& Glover, 1963) was used to prepare the labelled antigen. Protein $(5 \mu \mathrm{g}$ in $20 \mu \mathrm{l} 0.5 \mathrm{M}$-sodium phosphate buffer) was reacted with $100 \mu \mathrm{g}$ chloramine-T in $20 \mu \mathrm{l} 0.05 \mathrm{M}$-sodium phosphate buffer and $0.5 \mathrm{mCi}^{125} \mathrm{I}$ for $60 \mathrm{sec}$. For FSH $10 \mu \mathrm{g}$ chloramine-T were used and the reaction lasted $10 \mathrm{~min}$. This was done to preserve the protein. The reaction was terminated by the addition of $200 \mu \mathrm{g}$ sodium metabisulphite and $500 \mu \mathrm{g} \mathrm{KI}$ plus $500 \mu \mathrm{g}$ BSA, each in $100 \mu 10.05 \mathrm{M}$-sodium phosphate buffer. Purification was carried out on Sephadex (Pharmacia Ltd, Hounslow, Middlesex TW3 1NE, U.K.) G25 and G100 columns. Aliquants $(20 \mu \mathrm{l})$ of plasma were assayed in duplicate with anti-rabbit FSH (AFP-4-7-21-76) and LH (AFP-8-1-28) raised in guinea-pigs and diluted in 1:600 normal guinea-pig serum. The antiserum $(20 \mu \mathrm{l})$ and label $(5000$ c.p.m. in $20 \mu \mathrm{l})$ were added to the assay tubes simultaneously. After incubation for $24 \mathrm{~h}$ at $4^{\circ} \mathrm{C}, 20 \mu \mathrm{l}$ of 1:40 anti-guinea-pig precipitating serum (Wellcome Reagents Limited, Beckenham, BR3 3BS, U.K.) were added. A further incubation for $24 \mathrm{~h}$ at $4^{\circ} \mathrm{C}$ was followed by the addition of $200 \mu \mathrm{l}$ assay diluent and centrifugation at $1700 \mathrm{~g}$ for $30 \mathrm{~min}$. The precipitate was then counted for 1 min after removal of the supernatant.

All the samples were assayed simultaneously for each hormone. The standard range in both assays was 0.05 and $25 \mathrm{ng} / \mathrm{ml}$. The coefficients of variation were $15.61 \%$ and $14.17 \%$ for FSH and LH respectively. The sensitivity was 0.19 and $0.78 \mathrm{ng} / \mathrm{ml}$ respectively. In both assays the value of the blank (assay buffer) was less than the assay sensitivity. The FSH antiserum cross-reacted with rabbit LH (0.04\%) and with rabbit TSH (AFP-561-c) (0.6\%). The LH antiserum cross-reacted with the rabbit TSH $(2 \cdot 8 \%)$ and not significantly with the rabbit FSH.

Calculations and statistical procedures. An index of testicular weight (I), derived from the length (L) and width (W) measurements and given by:

$$
I=\log \left(\pi \cdot(\mathrm{W} / 2)^{2} \cdot \mathrm{L}\right)
$$

was calculated. In 16 cases, testes were obtained from adult male wild rabbits in which the testicular dimensions of length, width and weight were known. When regressed against weight by using a linear model, the index of testicular weight provided a good approximation of true testicular weight $(r=0.96)$. Testicular size was then expressed as an estimated testicular weight derived from this relationship (estimated weight $=(I+0 \cdot 2336) / 0 \cdot 2997)$.

Differences between groups were evaluated with two-tailed $t$ tests, and a probability of 0.05 was assumed to be significant. Repeated measures analysis of variance was used to evaluate changes in the testicular size and hormone concentrations with time.

\section{Results}

\section{Testicular weight}

After the start of the pretreatment in $8 \mathrm{~L}: 16 \mathrm{D}$, testicular weight increased significantly $(P<0.001)$ and reached an asymptote in all groups of rabbits. There was no significant difference between the testicular weights of all the groups in Week 5 , when the experimental treatments began, or in the week when the asymptotic testicular weight was reached (Table 1). The mean increase in testicular weight also did not differ significantly between the groups, but testes in Groups $3 \mathrm{~b}$ and $3 \mathrm{c}$ reached asymptotic weight before those in the other groups because they had higher rates of growth (Table 1). There was a trend in growth rate with rabbits in Group 1, in 8L:16D, having the lowest overall rate of testicular growth, while those in Group 3c, in $20 \mathrm{~L}: 4 \mathrm{D}$, had the greatest rate of growth.

The testicular weight of rabbits kept in short daylengths (Group 1) increased until it reached an asymptote about Week 22 (Fig. 1a). There was significant variation in the testicular weight of 
Table 1. Comparison between the growth rate of the testes of male wild rabbits in Group 1 (8L:16D), Group 2 (13L:11D), Group 3a (13L:11D after 8 weeks in 20L:4D),

Group 3b (13L:11D after 16 weeks in 20L:4D) and Group 3c (20L:4D)

\begin{tabular}{lccccc}
\hline Group & $\begin{array}{c}\text { Wt }(\mathrm{g}) \\
\text { (week 1) }\end{array}$ & $\begin{array}{c}\text { Asymptotic } \\
\text { wt (g) }\end{array}$ & $\begin{array}{c}\text { Time to } \\
\text { reach } \\
\text { asymptote } \\
\text { (weeks) }\end{array}$ & $\begin{array}{c}\text { Weight } \\
\text { increase } \\
(\mathrm{g})\end{array}$ & $\begin{array}{c}\text { Mean } \\
\text { rate } \\
\text { (g/week) }\end{array}$ \\
\hline 1 & $1.80 \pm 0.16$ & $2.78 \pm 0.1$ & 22 & $1.05 \pm 0.19$ & $0.05 \pm 0.01 \dagger$ \\
2 & $1.50 \pm 0.18$ & $2.74 \pm 0.06$ & 22 & $1.24 \pm 0.22$ & $0.06 \pm 0.01$ \\
3a & $1.48 \pm 0.25$ & $2.62 \pm 0.18$ & 22 & $1.14 \pm 0.33$ & $0.05 \pm 0.02$ \\
3b & $1.63 \pm 0.34$ & $2.75 \pm 0.07$ & 16 & $1.12 \pm 0.30$ & $0.07 \pm 0.02$ \\
3c & $1.81 \pm 0.12$ & $2.87 \pm 0.09$ & 14 & $1.06 \pm 0.09$ & $0.08 \pm 0.01$ \\
\hline
\end{tabular}

Values are mean \pm s.e.m. for 6 (Groups $1 \& 2$ ) or 4 (Groups $3 \mathrm{a}, 3 \mathrm{~b}, 3 \mathrm{c}$ ) rabbits.

$\dagger$ Group 1 significantly less than Group $3 \mathrm{c}(\mathrm{t}=2.325$, d.f. $=8, P<0.05)$.

Group 1 rabbits from Week 22 to the end of the experiment $(\mathrm{F}(11,55)=2 \cdot 315, P<0 \cdot 05)$, but this showed no distinctive pattern. The testicular weight of rabbits transferred to $13 \mathrm{~L}: 11 \mathrm{D}$, after 5 weeks in $8 \mathrm{~L}: 16 \mathrm{D}$, continued to increase after the transfer and reached an asymptote in Week 22 (Fig. 1a). There was significant variation in the testicular weight after Week 22 (Group 2, F(11,55) = 3.617, $P<0.01)$ and, in Weeks 26-33, the testicular weights of Group 2 were significantly lower than those of Group 1.

The testicular weight of rabbits in Group 3a reached an asymptote in Week 22 (Fig. 1b), but this value did not differ significantly from those for Groups 1 and 2 during, and after, Week 22 and there was no significant variation in testicular weight during this time $(F(11,33)=0 \cdot 847$, $P>0.05$ ). The testicular weights of rabbits in Groups $3 \mathrm{~b}$ and $3 \mathrm{c}$ reached an asymptote in Weeks 16 and 14 respectively (Fig. 1c). In both groups, there was a significant decline in testicular weight (Group 3b, Weeks 16-21, F $(5,15)=3.062, P<0.05$; Group 3c, Weeks 14-21, F $(7,21)=2.910$, $P<0.05)$ immediately after the asymptotic testicular weight had been reached. Up to Week 21 , males in Groups $3 \mathrm{~b}$ and $3 \mathrm{c}$ had received identical treatments and testicular weight had shown a similar pattern of variation in both Groups. However, after Week 21, when Group 3b was transferred to $13 \mathrm{~L}: 11 \mathrm{D}$, there was a significant decline in the testicular weight (Weeks 22-25, $\mathrm{F}(3,9)=8.241, P<0 \cdot 01)$. During Weeks $24-30$ the testicular weight of Group $3 \mathrm{~b}$ was significantly less than the testicular weight of Group $3 \mathrm{c}$ (e.g. Week $25, \mathrm{t}=6.836$, d.f. $=6, P<0.001$ ). The pattern and time-course of the testicular regression in Group 3b after transfer from 20L:4D to 13L:11D (Week 21) involved an initial rapid regression and by Week 24 testicular weight was not significantly different from that in Week $1(\mathrm{~F}(1,3)=3 \cdot 391, P>0.05)$. This was followed by a significant redevelopment of the testis (Weeks $25-33, \mathrm{~F}(8,24)=3.636, P<0.01$ ) 9 weeks after the transfer of 13L:11D. The testicular weight of rabbits in Group 3b returned to a size similar to that of Group 3c during Weeks 31-33 $(P>0.05)$. The testicular weight of Group 3c did not show significant variation during Weeks $22-33(\mathrm{~F}(11,33)=1 \cdot 115, P>0 \cdot 05)$.

\section{Plasma FSH, $\mathrm{LH}$, and testosterone}

No significant variation in the plasma LH concentration occurred during the experiment $(P>0.05)$. Plasma testosterone varied significantly only in Groups 3a $(\mathrm{F}(11,33)=2 \cdot 647$, $P<0.05)$ and $3 \mathrm{~b}(\mathrm{~F}(11,33)=3.122, P<0.01)$ and not in the other 3 groups. Plasma FSH varied significantly in all groups $(P<0.01)$ during the experiment and generally showed increasing concentrations at the start followed by a period when values remained elevated. This corresponded 


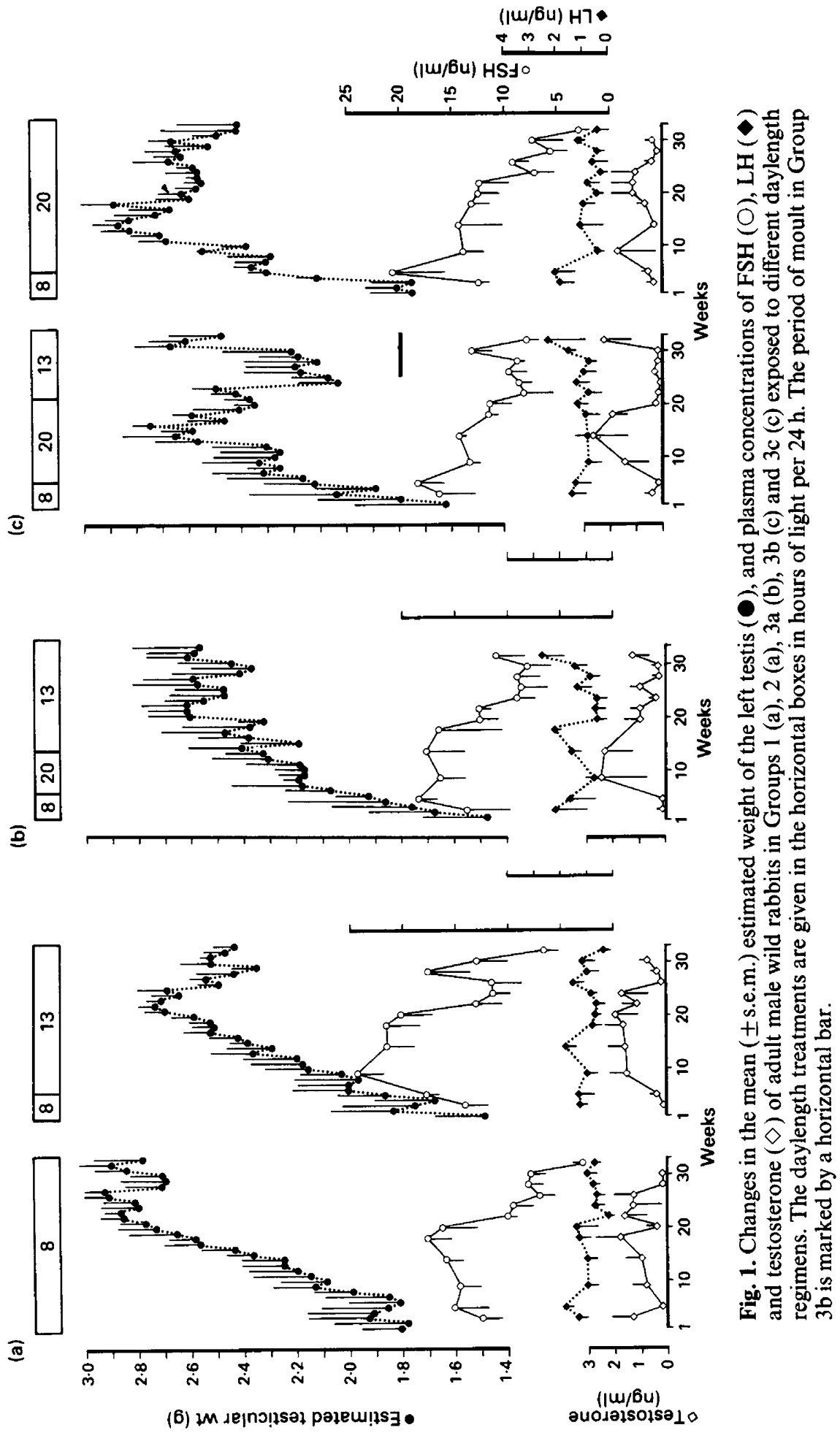


with the phase of rapid testicular growth. There was then a decline in plasma FSH when testicular size was large (Fig. 1). The pattern of plasma FSH concentrations was similar in Groups $3 \mathrm{~b}$ and $3 \mathrm{c}$, but these groups appeared to differ from the other 3 groups. In Groups 1, 2 and 3a, plasma FSH increased or remained constant over the first 20 weeks. This was followed by a decline and levels remained low for the remainder of the experiment except in Group 2. Here, there was a transient significant increase $(\mathrm{F}(1,5)=9.761, P<0.05)$ followed by a significant decline $(\mathrm{F}(2,10)=4.939$, $P<0.05)$ in plasma FSH. This increase corresponded with a period of slight testicular growth. In Groups $3 \mathrm{~b}$ and $3 \mathrm{c}$, plasma FSH was in a steady decline from Week 5. The plasma FSH concentrations in these two Groups were significantly different only during Weeks 28,30 and 32 $(P<0.02)$, when FSH values were greater in Group 3b. This corresponded to a period of testicular growth in Group 3b.

\section{Moult}

Moulting occurred to some degree in all groups except Group 1. In Group 2, 4 of the 6 rabbits began to moult in Week 28. In Group 3a, 1 of the 4 rabbits began to moult in Week 32 and in Group 3c, 1 of the 4 rabbits began to moult in Week 28 and another began in Week 32. In Group $3 \mathrm{~b}$, all the rabbits began to moult during weeks 26-28 (Fig. 1c).

\section{Discussion}

This study has shown that a daylength of $13 \mathrm{~L}: 11 \mathrm{D}$ can be both stimulatory and inhibitory to testicular growth in wild rabbits, depending upon the previous experience of daylength. After exposure to a long day (20L:4D) for 8 weeks, transfer to $13 \mathrm{~L}: 11 \mathrm{D}$ failed to induce testicular regression but it did alter the pattern of testicular growth from those rabbits remaining in $20 \mathrm{~L}: 4 \mathrm{D}$ (Fig. 1b). Transfer to 13L:11D after a further 8 weeks resulted in testicular regression, moult and testicular development. This type of response is typical of mammals which have breeding seasons in the spring and summer (Turek \& Campbell, 1979; Johnston \& Zucker, 1980; Reiter, 1980; Lynch \& Wichman, 1981; Carter, Hall, Tamarkin \& Goldman, 1982) including wild rabbits (Boyd, 1985). These results are similar to some obtained for Japanese quail (Robinson \& Follett, 1982).

The regression-regrowth response observed in Group 3b rabbits, after 16 weeks in 20L:4D, was less pronounced than in a previous study (Boyd, 1985). This may have been due to the relatively longer daylength used in this study (13L:11D compared with $8 \mathrm{~L}: 16 \mathrm{D}$ ) to induce testicular regression.

Daylength was unimportant in determining whether the testes of rabbits grew from the start of the experiment. This is consistent with the view that the start of the breeding season is due to spontaneous testicular regrowth (Reiter, 1980; Zucker et al., 1980) after a period of regression. The initial increase in plasma FSH concentration shows that the start of the study coincided with the reactivation of the pituitary-gonadal axis.

The overall rate of testicular growth was greater in the groups exposed to long days than in those given short days, although the asymptotic testicular weight did not vary with daylength. Similar results have been obtained for Japanese quail (Follett \& Maung, 1978). This shows that, during the period of testicular redevelopment, wild rabbits are responsive to daylength. The different rates of testicular growth were reflected in the concentration of plasma FSH, which remained elevated for longer in rabbits in $8 \mathrm{~L}: 16 \mathrm{D}$ and 13L:11D, than in 20L:4D. The decline in FSH after the asymptote of testicular size may be an effect of negative feedback by gonadal steroids. However, the concentration of plasma testosterone showed little variation during the experiment although in Groups $3 a$ and $3 b$ there were significant peaks of plasma testosterone before the asymptote of testicular size. This was reflected in the low levels of plasma LH which occurred throughout the 
study. Moor \& YoungLai (1975) found no diurnal variation in plasma LH and testosterone in male domestic rabbits, but did find episodic release of both hormones. The concentrations of $\mathrm{LH}$ and testosterone found in this study were lower than found by Moor \& YoungLai (1975). One explanation for these low levels may be that they resulted from short-term stress caused by handling and anaesthetizing the rabbits when taking blood samples. Plasma FSH may be less affected by shortterm stress and provides the most reliable variable for comparing the endocrine response to daylength manipulations with the morphometric changes in the testes, which have been shown to reflect the occurrence of spermatogenesis (Boyd, 1985).

The transient increase that occurred in plasma FSH concentration late in the experiment in Group $3 b$ corresponded with a time of testicular redevelopment although a similar rise in FSH in Group 2 was associated with only a slight increase in testicular size. This information, together with the occurrence of moult in Group 3b at this time (Boyd, 1985), supports the conclusion that the transfer of the males in Group $3 \mathrm{~b}$ to $13 \mathrm{~L}: 11 \mathrm{D}$, after 16 weeks in 20L:4D, caused the type of testicular regression and redevelopment normally induced by exposure to short days. The time interval between the change in daylength and the onset of testicular development was similar to that found previously for wild rabbits (Boyd, 1985).

In Groups 2, 3b and $3 \mathrm{c}$ testicular size reached a peak after the initial phase of growth and this was followed by a slight but significant decline. This may have been a result of continuous exposure to long days, since regrowth of the testes normally occurs in short winter daylengths. Testicular growth may then occur so rapidly that, by the time gonadal steroid negative feedback is in operation, the testes will have exceeded their normal active size.

Wild rabbits do not have a reproductive cycle which is dependent upon the inductive or non-inductive effects of absolute daylength. Studies of other species have led to conclusions that there is a critical absolute daylength below which there is reproductive regression when preceded by an appropriate period of photostimulation (Elliott, 1976; Follett \& Maung, 1978; Grocock, 1981). This study has shown that the critical daylength in wild rabbits depends upon this period of photostimulation. Exposure to long daylengths during the spring and summer may increase this daylength threshold. This is similar to the hypothesis proposed by Robinson \& Follett (1982) for Japanese quail. If such a mechanism was to operate under the control of a circadian cycle of photosensitivity (Pittendrigh \& Minis, 1964; Grocock \& Clarke, 1974; Grocock, 1981; Almeida \& Lincoln, 1982), it would probably have to involve a gradual change in the position or length of the photosensitive phase in accordance with the current daylength. Under natural conditions, the termination of breeding each year is probably caused by a convergence of the daylength threshold, which increases under long summer daylengths, with the ambient daylength. This convergence is complete when the ambient daylength begins to decline after the summer solstice, resulting in testicular regression.

I thank Dr A. S. Dawson, Professor B. K. Follett, Dr A. R. Goldsmith and Dr T. J. Nicholls for helpful comments on this work and Dr A. S. Dawson for reading the manuscript. Dr A. F. Parlow kindly supplied the LH and FSH antigens and antisera.

\section{References}

Andersson, M., Dahlback, M. \& Meurling, P. (1979) Biology of the wild rabbit, Oryctolagus cuniculus, in southern Sweden. I. Breeding season. Swedish Wildl. Res. 11, 103-127.

Almeida, O.F.X. \& Lincoln, G.A. (1982) Photoperiodic regulation of reproductive activity in the ram: evidence for the involvement of circadian rhythms in melatonin and prolactin secretion. Biol. Reprod. 27, 1062-1075.
Arthur, C.P. (1980) Demographie du lapin de garenne Oryctolagus cuniculus (L) 1758 en region Parisienne. Bull. mens. off. Natiom. Chasse, No. Sp. Scien. Tech., Decembre 1980, 127-162.

Boyd, I.L. (1985) Effect of photoperiod and melatonin on testis development and regression in wild European rabbits (Oryctolagus cuniculus). Biol. Reprod. 33, 21-29.

Carter, D.S., Hall, V.D., Tamarkin, L. \& Goldman, B.D. 
(1982) Pineal is required for testicular maintenance in the Turkish hamster (Mesocricetus brandti). Endocrinology 111, 863-871.

Davies, D.T. \& Myhill, D.G. (1980) Rabbit enclosures: a viable scientific approach? An. Rep. Inst. ter. Ecol. 1979, 13-18.

Elliott, J.A. (1976) Circadian rhythms and photoperiodic time measurement in mammals. Fedn Proc. Fedn Am. Socs exp. Biol. 35, 2339-2346.

Follett, B.K. \& Maung, S.L. (1978) Rate of testicular maturation, in relation to gonadotrophin and testosterone levels, in quail exposed to various artificial photoperiods and to natural daylengths. $J$. Endocr. 78, 267-280.

Greenwood, F.C., Hunter, W.M. \& Glover, J.S. (1963) The preparation of ${ }^{125} \mathrm{I}$ human growth hormone in plasma. Nature, Lond. 199, 784-787.

Grocock, C.A. (1981) Effect of different photoperiods on testicular weight changes in the vole. Microtus agrestis. J. Reprod. Fert. 62, 25-32.

Grocock, C.A. \& Clarke, J.R. (1974) Photoperiodic control of testis activity in the vole, Microtus agrestis. $J$. Reprod. Fert. 39, 337-347.

Hamner, W.H. (1968) The photorefractory period of the house finch. Ecology 49, 211-227.

Henderson, B.A. (1979) Regulation of the size of the breeding population of the European rabbit, Oryctolagus cuniculus, by social behaviour. J. appl. Ecol. 16, 383-392.

Johnston, P.G. \& Zucker, I. (1980) Photoperiodic regulation of the testes of adult white-footed mice (Peromyscus leucopus). Biol. Reprod. 23, 859-866.
Lynch, G.R. \& Wichman, H.A. (1981) Reproduction and thermoregulation in Peromyscus: effects of chronic short days. Physiol. Behav. 26, 201-205.

Moor, B.C. \& YoungLai, E.V. (1975) Variations in peripheral levels of $\mathrm{LH}$ and testosterone in adult male rabbits. J. Reprod. Fert. 42, 259-266.

Pittendrigh, C.S. \& Minis, D.H. (1964) The entrainment of circadian oscillations by light and their role as photoperiodic clocks. Am. Nat. 98, 261-294.

Reiter, R.J. (1972) Evidence for refractoriness of the pituitary-gonadal axis to the pineal gland in golden hamsters and its possible implications in annual reproductive rhythms. Anat. Rec. 173, 365-372.

Reiter, R.J. (1980) The pineal and its hormones in the control of reproduction in mammals. Endocr. Rev. 1, 109-131.

Robinson, J.E. \& Follett, B.K. (1982) Photoperiodism in Japanese quail: the termination of seasonal breeding by photorefractoriness. Proc. R. Soc. Lond. B 215, 95-116.

Turek, F.W. \& Campbell, C.S. (1979) Photoperiodic regulation of neuro-endocrine-gonadal activity. Biol. Reprod. 20, 32-50.

Zucker, I., Johnston, P.G. \& Frost, D. (1980) Comparative, physiological and biochronometric analyses of rodent seasonal reproductive cycles. Prog. reprod. Biol. 5, 102-133.

Received 24 September 1985 